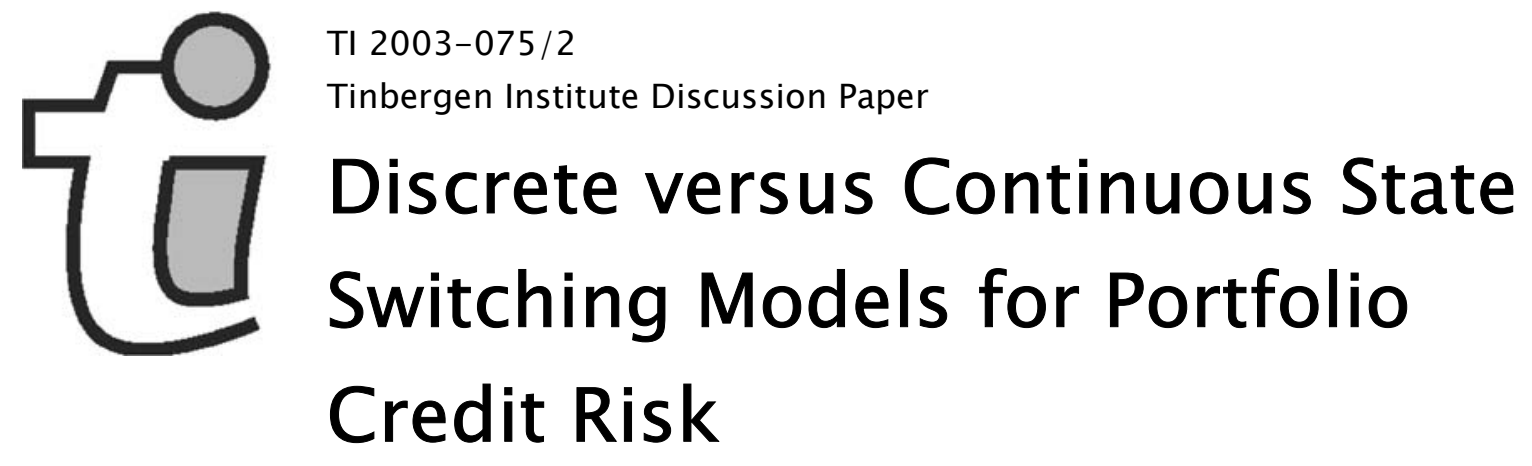

André Lucas'

Pieter Klaassen ${ }^{2}$

' Department of Finance, ECO/FIN, Faculty of Economics and Business Administration, Vrije Universiteit Amsterdam, and Tinbergen Institute.

2 Financial Markets Risk Management, ABN AMRO Bank NV, Amsterdam. 


\section{Tinbergen Institute}

The Tinbergen Institute is the institute for economic research of the Erasmus Universiteit Rotterdam, Universiteit van Amsterdam, and Vrije Universiteit Amsterdam.

Tinbergen Institute Amsterdam

Roetersstraat 31

1018 WB Amsterdam

The Netherlands

Tel.: $\quad+31(0) 205513500$

Fax: $\quad+31(0) 205513555$

Tinbergen Institute Rotterdam

Burg. Oudlaan 50

3062 PA Rotterdam

The Netherlands

Tel.: $\quad+31(0) 104088900$

Fax: $\quad+31(0) 104089031$

Please send questions and/or remarks of nonscientific nature to driessen@tinbergen.nl.

Most TI discussion papers can be downloaded at http://www.tinbergen.nl. 


\title{
Discrete versus Continuous State Switching Models for Portfolio Credit Risk*
}

\author{
André Lucas ${ }^{\dagger \ddagger}$ and Pieter Klaassen ${ }^{\S}$
}

This version: September 23, 2003

\begin{abstract}
Dynamic models for credit rating transitions are important ingredients for dynamic credit risk analyses. We compare the properties of two such models that have recently been put forward. The models mainly differ in their treatment of systematic risk, which can be modeled either using discrete states (e.g., expansion versus recession) or continous states. It turns out that the implied asset correlations for discrete state switching models are implausibly low compared to correlation estimates in the literature. Given these limited correlations, we conclude that care has to be taken when discrete state regime switching models are employed for dynamic credit risk management. As a side result of our analysis, we obtain indirect evidence that default correlations may change over the business cycle.
\end{abstract}

Key words: credit risk, regime switching, latent variable models, factor models.

JEL Codes: G21; C22; C53.

${ }^{*}$ We thank Bert Menkveld for useful comments on an earlier version of this paper. Correspondence to: alucas@feweb.vu.nl, p.klaassen@nl.abnamro.com.

${ }^{\dagger}$ Dept. of Finance, ECO/FIN Vrije Universiteit, De Boelelaan 1105, NL-1081HV Amsterdam, The Netherlands

${ }^{\ddagger}$ Tinbergen Institute Amsterdam, Roetersstraat 31, NL-1018 WB, Amsterdam, the Netherlands

${ }^{\S}$ ABN AMRO Bank NV, Financial Markets Risk Management (HQ 2035), P.O.Box 283, NL-1000EA, Amsterdam, the Netherlands 


\section{Introduction}

Credit risk management has evolved considerably over the past decade. Earlier work in the area was characterized by a dominant focus on credit scoring and static assessment of default probabilities, see for example Caouette, Altman, and Narayanan (1998). Though the evaluation of a counterparty's creditworthiness at the loan contracting stage is still very important, the increased number (and liquidity) of instruments and markets for credit risk has required a more dynamic approach to credit risk management. Trading derivatives on credit risky instruments, for example, requires dynamic hedging decisions. Also the possibility to securitize part of a bond or loan portfolio at flexible points in time provides banks with much more options for their credit risk management process. To evaluate the alternative options, models are needed to describe the evolution of key credit risk drivers such as default and credit rating migration probabilities, as well as recovery rates.

In this paper we concentrate on alternative model specifications that have been introduced for credit rating migrations. A credit rating summarizes the creditworthiness of the underlying firm. Credit rating transitions may vary with ecomic conditions. For example, following the empirical evidence in Nickell, Perraudin, and Varotto (2000) and Bangia, Diebold, Kronimus, Schagen, and Schuermann (2002), defaults and downgrades are more likely during recessions than during expansions. Time variation in transition probabilities, especially if correlated with economic conditions, may have an important impact. Under risk sensitive capital requirements as proposed in the new Basle Capital Accord (Basle Committee on Bank Supervision (2003)), capital buffers would have to be raised significantly if an expansion turns into a recession, see the numerical experiments in Bangia et al. (2002).

We distinguish two types of models in the literature for linking rating transition probabilities to economic conditions. They differ in their treat- 
ment of the state of the economy. Nickell et al. (2000) and Bangia et al. (2002) use discrete states. Bangia et al. (2002) for example use a panel data set on rating migrations and divide their sample into recession and expansion quarters. ${ }^{1}$ Next, they estimate separate probabilities for each regime. This approach is intuitively appealing and yields plausible results for the transition probabilities. However, the question remains whether the limited number of discrete states provides a rich enough characterization of portfolio credit risk. An alternative approach is to model the state of the economy as a continuous variable. This can be done using observed components as in for example Wilson (1997a,b) or Kavvathas (2001), Das, Freed, Geng, and Kapadia (2002), or unobserved components, see for example Jarrow and Turnbull (1995), Duffie and Singleton (1999), Finger (2000), or Koopman, Lucas, and Klaassen (2002). See also the overview paper of Allen and Saunders (2003).

To answer the question whether the discrete or continuous state modeling approach is more useful, we conduct a numerical experiment in the current paper. In particular we address the question whether discrete state models provide a sufficiently rich description of credit risk outcomes compared to typical models with continuous states. We do so by matching the empirically implied credit loss distribution of Bangia et al. (2002) to that of a standard one-factor credit loss model with continuous states. This can be achieved by varying the default probability and the likelihood of joint defaults in the factor model. The implied numerical default probabilities and asset correlations can subsequently be assessed with respect to their plausibility. We have the following main findings. First, the discrete state model has a low likelihood of joint defaults as measured through the implied asset correlations. These range from around $2 \%$ down to $0.5 \%$. In all cases, these figures are significantly below prescribed regulatory asset correlations, see Basle Committee on Bank Supervision (2003). They are also far below usual correlations $\left(R^{2}\right)$

\footnotetext{
${ }^{1}$ Nickell et al. (2000) also distinguish a middle regime.
} 
of around $20 \%$ in typical market model regressions, which is the relevant comparison, see for example Lucas, Klaassen, Spreij, and Straetmans (2001). Second, we find that asset correlations are higher conditional on the economy starting in a recession vis-à-vis an expansion. This corroborates recent findings by Das et al. (2002) using a different approach and data set. Deng et al. use model-based measures of individual default intensities using market and accounting data to estimate intensity correlations. By contrast, we use direct aggregate information on default and rating migrations. We conclude that care has to be taken when applying the current generation of regime switching credit risk models for capital allocation. On the one hand, a dichotomy in default regimes is intuitively appealing. One has to make sure, however, that the model induced range of annual credit losses has suffient breadth to reflect the actual risk in well-diversified credit portfolios, i.e., correlations must be sufficiently high. On the other hand, standard models with continuous state variables for the economy and constant asset correlations may be misspecified in that they do not acknowledge an increase in default correlations during recessions. This feature is better taken up by the proposed discrete state switching models.

The paper is structured as follows. The next section presents the model, the experimental set-up, and the main results. The final section concludes.

\section{Modeling framework}

Our basic framework is given by the Gaussian one-factor model for credit risk, see Gupton, Finger, and Bhatia (1997) and Gordy (2003). For completeness, we summarize the main model aspects we use in our analysis. We assume that the default event for firm $j$ is driven by a latent variable $S_{j}$. The default risk driver $S_{j}$ can be decomposed as

$$
S_{j}=\rho f+\sqrt{1-\rho^{2}} \varepsilon_{j},
$$


where $f$ and $\varepsilon_{j}$ are the systematic and firm-specific risk, respectively. Following Basle Committee on Bank Supervision (2003) and Gupton, Finger, and Bhatia (1997), $f$ and $\varepsilon_{j}$ are assumed independent and standard normal. The coefficient $\rho$ determines the relative weight of each of these risk factors in the default process. In a structural modeling setting of Merton (1974), the variable $S_{j}$ can be interpreted as the firm's equity value. In our current static set-up, however, this interpretation is not exclusive, and one might also give a reduced form interpretation to (1) as in Jarrow and Turnbull (1995) or Duffie and Singleton (1999). In a structural interpretation, however, note that the correlation between $S_{j}$ and $S_{k}$ for $k$ not equal to $j$ equals $\rho^{2}$. We therefore refer to $\rho^{2}$ as the asset correlation parameter. The higher $\rho^{2}$, the higher the likelihood of defaults occuring in clusters.

Using (1), we can model the default frequency in a straightforward way. Let $1_{A}$ denote the indicator function of the set $A$, then the default frequency $p_{n}$ in a portfolio of $n$ counterparties can be defined as

$$
q_{n}=\frac{1}{n} \sum_{j=1}^{n} 1_{\left\{S_{j}<c\right\}}
$$

where $c$ denotes the default boundary. We now take a large portfolio approximation to credit losses as in Lucas, Klaassen, Spreij, and Straetmans (2001). This approximation is reasonable as long as the portfolio size is sufficiently large $(n>200) .^{2}$ We have

$$
q=q(f)=\lim _{n \rightarrow \infty} q_{n} \stackrel{\text { a.s. }}{=} \mathrm{P}\left[S_{j}<c \mid f\right]=\Phi\left(\frac{c-\rho f}{\sqrt{1-\rho^{2}}}\right)
$$

with $\Phi$ denoting the standard normal cumulative distribution function (cdf). From (3) and the normality assumption for $f$, we can easily obtain the distribution of default frequencies. In particular, $\Phi^{-1}(q)$ is normally distributed

\footnotetext{
${ }^{2}$ Note that the granularity condition of Gordy (2003) is automatically satisfied here, as we consider default frequencies rather than losses.
} 
with mean $c / \sqrt{1-\rho^{2}}$ and variance $\rho^{2} /\left(1-\rho^{2}\right)$. Alternatively, if $\mu$ and $\sigma^{2}$ denote the mean and variance of $\Phi^{-1}(q)$, respectively, then

$$
\begin{aligned}
\rho^{2} & =\sigma^{2} /\left(1+\sigma^{2}\right), \\
c & =\mu / \sqrt{1+\sigma^{2}} .
\end{aligned}
$$

In our current analysis, we link model (1) based on a continuous state variable for current economic conditions to a model that uses discrete states. We focus on the model of Bangia et al. (2002). The main reason for this is that Bangia et al. not only provide estimates of transition matrices over different stages of the business cycle, but also a model for switches from one economic regime to the other. The framework of Bangia et al. builds upon the existence of two quarterly transition matrices $T^{r}$ and $T^{e}$, applicable in recessions and expansions, respectively. The $(i, j)$ th element $T_{i j}^{r}$, for example, gives the probability that a firm with initial rating $i$ migrates to rating $j$ over the next quarter, given that the next quarter will be a recession. The rating category with the highest index $j$ denotes the absorbing default state. To distinguish recessions from expansions, NBER classifications are used. To select the appropriate regime for a specific quarter, Bangia et al. estimate a simple regime switching model characterized by the transition matrices given in the note to Table 1 later on. Note that the intuition underlying this approach bears strong resemblance to (1) and (3). The main difference is that over a 4 quarter horizon, we only have 16 possible sequences of recessions and expansions, i.e., of the systematic risk factor, whereas the systematic risk factor $f$ in (3) takes continuous values. Both approaches, however, provide default frequencies contingent on the state of the economy.

It is difficult to compare the approach of Bangia et al. and (1) directly. To facilitate the comparison, we use relation (3) to cast the regime switching model into a one-factor structure. Note that for every sequence of (quarterly) recessions and expansions we obtain a conditional (on that sequence) default probability for a specific rating grade. For example, the last element of the 
top row of $\left(T^{r}\right)^{4}$ indicates the one-year default probability of an AAA firm over the next year, given that the next year only has recession quarters. Similarly, the last element of the second row of $\left(T^{e}\right)^{4}$ gives the one-year default probability of an AA rated firm, given that the next year only has expansion quarters. The probability of 4 recession (or expansion) quarters in a row directly follows from the regime switching model for the macro-economy, see Bangia et al. (2002) and Table 1. This probability may be either unconditional or conditional, i.e., conditional on the current quarter being a recession or expansion. The Bangia et al. approach thus produces 16 pairs $(q(\tilde{f}), p(\tilde{f}))$, where $\tilde{f}$ denotes the sequence of four recession or expansion quarters, $p(\tilde{f})$ denotes the probability of that sequence, and $q(\tilde{f})$ the conditional (on $\tilde{f}$ ) default probability. Given these 16 pairs we can use (4) to obtain maximum likelihood ${ }^{3}$ estimates of the unconditional default probability $p=\Phi(c)$ and the asset correlation $\rho^{2}$. I.e., we use the conditional default frequencies and corresponding regime probabilities to calibrate the unknown parameters in (3). This amounts to approximating the sequences' distribution $p(\tilde{f})$ by a transformed normal distribution, see Figure 1 for an example. We do so for different rating classes, different conditioning sets, and the two different regime switching models in Bangia et al. (2002). The results are in Table 1.

Table 1 reveals several interesting patterns. First we note the familiar increase in default probabilities $p$ if the rating declines. Also, the one year default probabilities are higher if we start from a current recession vis-àvis an expansion. This has also been documented in Nickell et al. (2000) and Bangia et al. (2002). Second, we find that asset correlations $\rho^{2}$ are uniformly low across ratings and sample periods. They range from $2.18 \%$

\footnotetext{
${ }^{3}$ More specifically, given our large-portfolio approximation, the estimates are obtained using asymptotic maximum likelihood maximization or Kullback-Leibler distance minimization. As a robustness check, we also used a simulation approach to estimate implied correlations accounting for both systematic and idiosyncratic risk. The results were the same as reported here.
} 
Table 1:

Implied asset correlations and default probabilities

for the Bangia et al. model

\begin{tabular}{|c|c|c|c|c|c|c|c|}
\hline Rating & AAA & $\mathrm{AA}$ & $\mathrm{A}$ & $\mathrm{BBB}$ & $\mathrm{BB}$ & B & $\mathrm{CCC}$ \\
\hline & \multicolumn{7}{|c|}{ Switching Model on 1959-1998 } \\
\hline & \multicolumn{7}{|c|}{ Unconditional } \\
\hline$p$ & 0.00 & 0.01 & 0.01 & 0.18 & 0.90 & 4.76 & 30.46 \\
\hline \multirow[t]{2}{*}{$\rho^{2}$} & 1.29 & 0.79 & 0.90 & 2.04 & 1.36 & 0.96 & 1.18 \\
\hline & \multicolumn{7}{|c|}{ Conditional: current expansion } \\
\hline$p$ & 0.00 & 0.01 & 0.01 & 0.18 & 0.87 & 4.68 & 30.12 \\
\hline \multirow[t]{2}{*}{$\rho^{2}$} & 1.06 & 0.64 & 0.87 & 1.95 & 1.27 & 0.88 & 1.07 \\
\hline & \multicolumn{7}{|c|}{ Conditional: current recession } \\
\hline$p$ & 0.00 & 0.01 & 0.01 & 0.21 & 0.99 & 5.08 & 31.75 \\
\hline \multirow[t]{3}{*}{$\rho^{2}$} & 1.95 & 1.16 & 1.01 & 2.18 & 1.55 & 1.12 & 1.43 \\
\hline & \multicolumn{7}{|c|}{ Switching Model on 1981-1998 } \\
\hline & \multicolumn{7}{|c|}{ Unconditional } \\
\hline$p$ & 0.00 & 0.01 & 0.01 & 0.17 & 0.86 & 4.63 & 29.98 \\
\hline$\rho^{2}$ & 0.91 & 0.61 & 0.74 & 1.71 & 1.10 & 0.75 & 0.91 \\
\hline & \multicolumn{7}{|c|}{ Conditional: current expansion } \\
\hline$p$ & 0.00 & 0.01 & 0.01 & 0.17 & 0.85 & 4.60 & 29.83 \\
\hline$\rho^{2}$ & 0.82 & 0.55 & 0.73 & 1.68 & 1.06 & 0.72 & 0.87 \\
\hline & \multicolumn{7}{|c|}{ Conditional: current recession } \\
\hline$p$ & 0.00 & 0.01 & 0.01 & 0.19 & 0.91 & 4.80 & 30.67 \\
\hline$\rho^{2}$ & 1.25 & 0.86 & 0.79 & 1.83 & 1.22 & 0.85 & 1.06 \\
\hline
\end{tabular}

Using the Gaussian one-factor (or CreditMetrics) model for credit risk, see Gupton et al. (1997) and Gordy (2003), we calibrate the unconditional default probability $p$ and 'asset correlation' $\rho^{2}$ to match the distribution of one-year default frequencies implied by the regime switching approach of Bangia et al. (2002). Figures are given as percentages. Calibrations are carried out for different initial ratings. The quarterly rating transition matrices applicable in expansions $\left(T^{e}\right)$ and recessions $\left(T^{r}\right)$ can be found in Bangia et al. (2002). The economic regime follows a quarterly two-state Markov chain (expansion/recession) characterized by $\left(\begin{array}{ll}0.848 & 0.152 \\ 0.575 & 0.425\end{array}\right)$ based on $1959-1998$ data (where 0.575 is the probability of switching from a recession to an expansion), and $\left(\begin{array}{cc}0.850 & 0.150 \\ 0.692 & 0.308\end{array}\right)$ based on 1981-1998 data. Unconditional means that the first quarter's state is drawn from the unconditional or stationary distribution. The conditional entries indicate that the current economic state is an expansion or recession, respectively. 


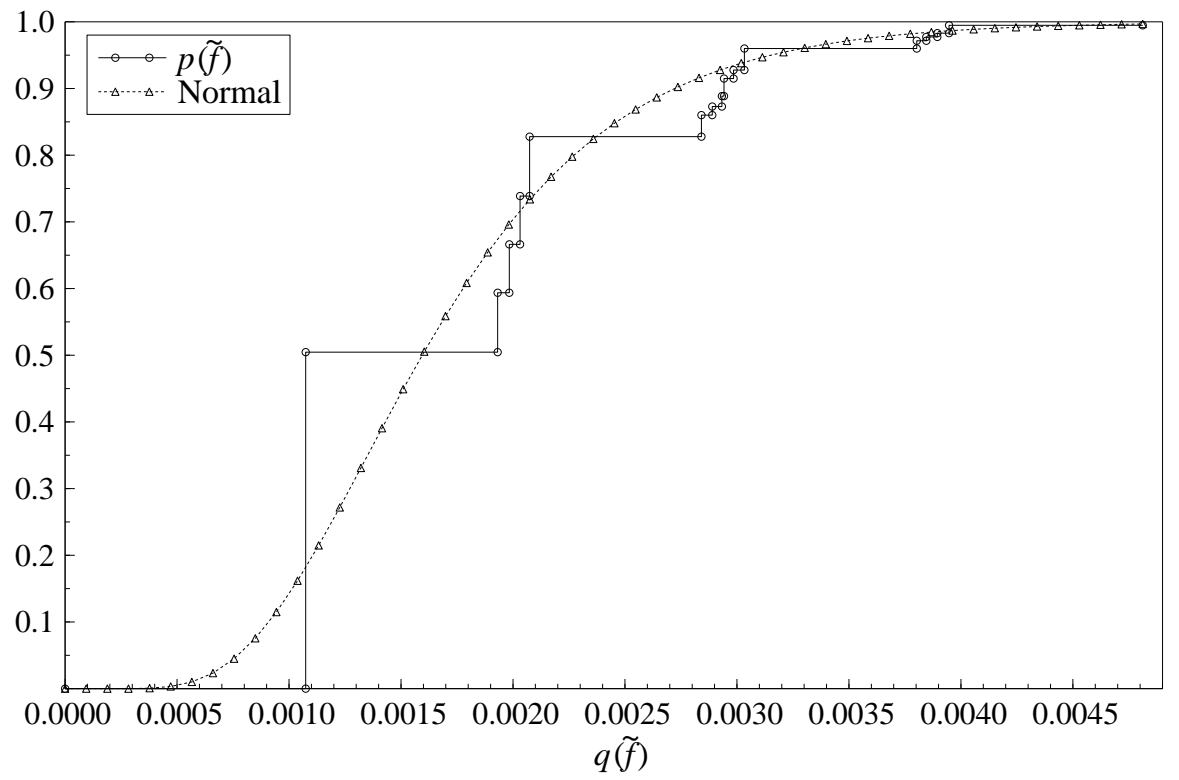

Figure 1: Bangia et al. and approximating normal distribution of conditional default rates for $\mathrm{BBB}$ rating

Given the quarterly recession/expansion regime switching model of Bangia et al. (2002) we obtain 16 different economic states $(\tilde{f})$ with conditional default probabilities $q(\tilde{f})$ in each state. The cdf of $q(\tilde{f})$ following from the Bangia et al. model provide the solid $p(\tilde{f})$ curve in the figure. The cdf is computed for a BBB rating with the first quarter's regime drawn from the unconditional distribution. Using (4), the default threshold $c$ and asset correlation $\rho^{2}$ are estimated to approximate $\Phi^{-1}(q(\tilde{f}))$ by a normal distribution. The resulting approximation $\Phi\left(\left(c-\sqrt{1-\rho^{2}} \Phi^{-1}(q(\tilde{f}))\right) / \rho\right)$ is depicted by the dashed curve.

for BBB rated firms that start in a recession (59-98 sample), to $0.55 \%$ for AA rated firms that start in expansions (81-98 sample). A clear pattern in the size of correlations across rating grades is lacking. In all cases, however, correlations appear substantially below the asset correlations put forward in the new Basle proposals. The correlations also appear low if they are interpreted as true asset correlations. For example, typical asset correlations for US stocks have their mode between $15 \%$ and 25\%, see Lucas et al. (2001). Taken together, this leads to the conclusion that care has to be taken if discrete state regime switching models are employed for dynamic credit risk management and capital requirements. The effective spread in outcomes of 
such models may be insufficient to adequately reflect the macro-economic risk at a portfolio level. To overcome these potential hazards, one might look for a finer distinction between different economic regimes. Alternatively, common risk factors might be captured using continuous rather than discrete state variables. A third finding from Table 1 is that the sample period for estimating the macro-economic risk dynamics has important consequences for parameter estimates. Using the longer sample period, we see that the estimated correlations are uniformly higher. This is an important finding given that many recent research on rating migrations concentrates on the shorter time horizon because of data availability. If such data are used, asset and default correlations between obligors might be underestimated due to limited variability in the macro-system over the period chosen. A fourth and final interesting feature emerging from Table 1 is that correlations appear higher in recessions than expansions. This closely follows the findings on default correlations in Das et al. (2002). Though their modeling framework and data used is entirely different, they also report that during economic downswings, default correlations are higher as firms are more likely to be pushed into default (simultaneously) due to economy-wide risk factors. In upswings, by contrast, rating movements are much more firm-specific and contain less common factors. This is corroborated by the computations based on the direct aggregate default and rating migration data underlying Table 1.

\section{Conclusion}

In this paper we have used a simple mapping to cast discrete state regime switching models for credit risk into a continuous state factor model structure. We used this approach to study the implied default probabilities and asset correlations of the regime switching approach of Bangia et al. (2002). We found that correlations implied by the model are low, and may appear 
too low given typical estimates of asset correlations in the literature. This cautions the use of these models for credit risk management and capital determination. A careful inspection is needed to guarantee that the spread in economic outcomes of a regime switching model adequately captures the true credit risk at a portfolio level. Our results also showed that correlations estimated using the past twenty years of data are uniformly lower than estimates based on a longer time span of 40 years or more. Again, this raises questions as to the robustness of empirical analyses based on data commonly starting in the early 80s. Finally, using our framework and data we corroborated the findings of Das et al. (2002): asset and default correlations appear to be higher in recessions than in expansions. This is to some extent captured by the regime switching approach, but not by the standard continuous state models with constant correlations. The latter should therefore be augmented to include state variation in correlations as well.

\section{References}

Allen, L. and A. Saunders (2003). A survey of cyclical effects in credit risk measurement models. Technical report, BIS Working Paper 126.

Bangia, A., F. Diebold, A. Kronimus, C. Schagen, and T. Schuermann (2002). Ratings migration and the business cycle, with application to credit portfolio stress testing. Journal of Banking and Finance 26(2-3), 445-474.

Basle Committee on Bank Supervision (2003, January). The new Basel capital accord. Report, Bank of International Settlements, Basle.

Caouette, J., E. Altman, and P. Narayanan (1998). Managing credit risk. The next great financial challenge. New York: Wiley.

Das, S. R., L. Freed, G. Geng, and N. Kapadia (2002). Correlated default risk. Technical report, Santa Clara University.

Duffie, D. and K. Singleton (1999). Modeling the term structures of defaultable bonds. Review of Financial Studies 12, 687-720.

Finger, C. (2000). A comparison of stochastic default rate models. RiskMetrics Jour- 
nal 1(2), 49-73.

Gordy, M. B. (2003). A risk-factor model foundation for ratings-based capital rules. Journal of Financial Intermediation 12(3), 199-232.

Gupton, G., C. Finger, and M. Bhatia (1997). CreditMetrics - Technical Document (1st ed.). http://www.riskmetrics.com.

Jarrow, R. and S. Turnbull (1995). Pricing derivatives on financial securities subject to credit risk. Journal of Finance (50), 53-85.

Kavvathas, D. (2001). Estimating credit rating transition probabilities for corporate bonds. Job market paper. http://www.ssrn.com/fen.

Koopman, S., A. Lucas, and P. Klaassen (2002). Pro-cyclicality, empirical credit cycles, and capital buffer formation. Technical Report TI Discussion paper 02-107/2, Tinbergen Institute, Amsterdam.

Lucas, A., P. Klaassen, P. Spreij, and S. Straetmans (2001). An analytic approach to credit risk of large corporate bond and loan portfolios. Journal of Banking and Finance 25, 1635-1664.

Merton, R. (1974). On the pricing of corporate debt: the risk structure of interest rates. Journal of Finance 29, 449-470.

Nickell, P., W. Perraudin, and S. Varotto (2000). Stability of rating transitions. Journal of Banking and Finance 24(1-2), 203-227.

Wilson, T. (1997a, September). Portfolio credit risk, part I. Risk, 111-117.

Wilson, T. (1997b, October). Portfolio credit risk, part II. Risk, 56-61. 